\title{
Cocoa Butter Substitute Production by Mixing the Fraction of Palm Kernel Stearin with Tengkawang Fat
}

\author{
Mursalin Mursalin ${ }^{1, *}$ Yernisa Yernisa ${ }^{2}$ \\ ${ }^{1}$ Department of Agricultural Technic, Faculty of Agriculture, Jambi University, Jalan Raya Jambi-Muara Bulian \\ Km.15 Mendalo Darat, Jambi 36122. \\ ${ }^{2}$ Department of Agricultural Industry Technology, Faculty of Agriculture, Jambi University, Jalan Raya Jambi- \\ Muara Bulian Km.15 Mendalo Darat, Jambi 36122. \\ *Corresponding author. Email: mursalin@ unja.ac.id
}

\begin{abstract}
In the chocolate and confectionary industry, there are several types of alternative fats to replace cocoa butter (CB), including cocoa butter substitute (CBS). CBS is a CB substitute fat derived from lauric fat, namely coconut oil (CNO) or palm kernel oil (PKO) which is modified physically (fractionated) or chemically (hydrogenation and interesterification). The most suitable part of PKO for making CBS is the stearin fraction (PKOs) which has an iod value (IV) of 5-7. Fractionation PKO at $19^{\circ} \mathrm{C}$ for 210 minutes produced $42 \%$ of PKOs with IV 5-7. PKOs were then blended with tengkawang fat (LT) with 5 levels of comparison (PKOs:LT), namely (70:30), (60:40), (50:50), (40:60), and (30:70) to saw the CBS characteristics. The parameters observed were melting point, solid fat content profile (SFC), and organoleptic properties of CBS (color, taste, and overall acceptance). The study was arranged in a completely randomized design with 3 replications. Variance analysis was carried out to see whether there were differences between treatments. Furthermore, to find out the best treatment, a further test was carried out using DNMRT at the 5\% level. The results showed that the ratio (PKOs: LT) greatly influenced the characteristics of the CBS produced. In compositions with the amount of PKOs equal to or slightly more than LT, the resulting CBS melting point and SFC profile were closer to the melting point and SFC profile of CB. Thus it could be concluded that to produce CBS with a profile that has the closest physical properties to CB could be obtained from blending PKOs with LT in the ratio (40:60) or (30:70).
\end{abstract}

Keywords: blending fat, cocoa butter substitutes, exotic fat, fat practionation, tengkawang.

\section{INTRODUCTION}

Since the demand for $\mathrm{CB}$ is increasing while its supply is decreasing, the price of $\mathrm{CB}$ become very high [1], [2]. Therefore, the chocolate and confectionary industries are moved to look for alternative fats to replace $\mathrm{CB}$. There are several types of alternative fat substitutes for $\mathrm{CB}$, such as cocoa butter equivalents (CBE), cocoa butter replacer (CBR), and cocoa butter substitutes (CBS).

CBE has chemical and physical properties that are very similar to $\mathrm{CB}$ and are compatible with each other so that it can be mixed without any amount limitation. CBR and CBS have very different chemical properties from $\mathrm{CB}$ but have very similar physical properties. Being solid phase at ambient temperature and quickly melting when it has been put inside the mouth. CBR is derived from non-lauric vegetable fats that are modified physically (fractionated) or chemically (hydrogenation and interesterification). CBS is made with the same way as CBR but it comes from lauric fat, namely coconut oil (CNO) or palm kernel oil (PKO).

Physical modification processes, such as fractionation and blending, are more preferred in developing alternative fat production to replace CB. Calliauw et al. [3], applied a two-stage fractionation in a pilot plant scale to PKO with iodine value (IV) 18. As a result, there are three kinds of fractions with different IVs, namely $29 \%$ in the form of PKOs IV 5 which could be directly used as CBS, $58 \%$ in the form of PKOo IV 27, 
and $13 \%$ are PKOs IV 7 which could be used as CBS once fully hydrogenated.

Alternative $\mathrm{CB}$ can also be produced from the fractionation and blending or enzymatic interesterification processes of PKO and PO [4], [5], [2]; mango seed fat [6], [7], [8]; kokum butter [9], [10]; Sal fat [11], [12], [13]; Shea butter [14]; and tengkawang fat [11].

Gunstone [11] reports that interesterification on sal fat (Shorea robusta), which is a type of fat similar to tengkawang fat, will produce fat with a triacylglycerol structure similar to $\mathrm{CB}$ and can be classified as CBE. Reddy and Prabhakar [10] produced alternative CBS by blending stearin from sal fat with phulwara butter in various comparisons. Their results showed that the characteristics of the density and profile of solid fat content (SFC) that were closest to $\mathrm{CB}$ were a mixture of $75-85 \%$ sal fat with $15-25 \%$ phulwara butter stearin.

Palm kernel oil stearin fraction (PKOs) is classified as a soft stearin with a melting point ranging from 29-31 ${ }^{0} \mathrm{C}$ while tengkawang fat is classified as solid fat with a melting point ranging from $38-40{ }^{\circ} \mathrm{C}$. If PKOs blend with tengkawang fat in a proper proportion, it will produce fat with melting properties similar to $\mathrm{CB}$. This study aims to determine the proportion of the mixture of PKOs and tengkawang fat in order to make CBS which is closest to the melting properties of CB.

\section{MATERIALS AND METHOD}

The materials used in this study were the PKOs and tengkawang fat as the main ingredients and various types of reagents, catalysts, and chemicals for analysis. The tools used include oil extractors, oil refiners, oil fractionators, analytical scales, stopwatches, digital thermometers, hot plates, beakers, cups, desiccators, Erlenmeyer, drop pipettes, digital refractometers, and glassware for analysis.

The PKOs used had an iodine value range of 6.8-8.8 and a melting point (SMP) of $29.70-30.50{ }^{\circ} \mathrm{C}$. The tengkawang fat used came from the extraction of Shorea macrantha seed, obtained from Lubuk Kepayang Village, Air Hitam District, Sarolangun Regency, Jambi with the local name Sengkawang. This tengkawang fat had an iodine value of 6.83 and a melting point (SMP) ranging from $38.20-39.80{ }^{\circ} \mathrm{C}$.

CBS resulted from a blending of PKOs and tengkawang fat was carried out by experiment. The effect of blending composition (K) was observed for the CBS characteristics resulted. The five types of blending composition consisted of PKOs fat ratio with tengkawang fat as the followings: $30 / 70(\mathrm{~K} 1)$; 40/60 (K2); 50/50 (K3); 60/40 (K4); and 70/30 (K5). For K1, 60 g PKOs were blended with $140 \mathrm{~g}$ of tengkawang fat in a glass beaker at $45^{\circ} \mathrm{C}$ for 30 minutes. After that, the blending was poured into square box covered by alluminium foil. The box was left at ambient temperature for 4 hours. Then, the boxes were put into refrigerate for 24 hours, before being analyzed. For $\mathrm{K} 2$ to $\mathrm{K} 5$, the treatment given was the same, the difference was only at the blending composition of PKOs and tengkawang fat. The PKOs/tengkawang fat ratio $(\mathrm{w} / \mathrm{w})$ for $\mathrm{K} 2, \mathrm{~K} 3, \mathrm{~K} 4$, and K5 were $80 / 120 ; 100 / 100 ; 120 / 80 ;$ and 140/60, respectively. The parameters observed were yield, melting point (SMP), and iodine number.

\section{RESULT AND DISCUSSION}

The characteristics of CBS products resulting from various compositions of PKOs and tengkawang fat were presented in Table 1.

Table 1. CBS characteristics

\begin{tabular}{|l|c|c|c|}
\hline \multirow{2}{*}{ PKOs/TF } & \multicolumn{3}{|c|}{ Parameters } \\
\cline { 2 - 4 } & Yield (\%) & IV & SMP $\left({ }^{\circ} \mathbf{C}\right)$ \\
\hline $30 / 70$ & 98,80 & 7,20 & 33,27 \\
\hline $40 / 60$ & 98,50 & 7,27 & 33,20 \\
\hline $50 / 50$ & 98,37 & 7,40 & 32,90 \\
\hline $60 / 40$ & 98,00 & 7,50 & 32,37 \\
\hline $70 / 30$ & 98,23 & 7,63 & 31,90 \\
\hline
\end{tabular}

In Table 1, the more PKOs in the blending, the CBS yield tended to decrease, although the amount of this decrease was not significant. It was assumed because PKOs were easily stick to processing equipment or accumulated during processing. Therefore, the greater the amount of PKOs in the composition, the CBS yield was low. The relationship was presented in Figure 1.

The more PKOs used has resulted the decrease of CBS slip melting point (SMP). SMP is one of the important parameters for CBS products. SMP will provide a description of the product melting properties. According to Lida and Ali [15], the fat in the capillary tube will slip when the solid fat content is around 4-5\%, so it can be analogized that SMP shows the condition when the fat has an SFC value of around $4-5 \%$. According to Yanty et al. [16], CB has an SFC value of $4-5 \%$ in the temperature range of $28.5-29.5^{\circ} \mathrm{C}$; which means that the SMP of $\mathrm{CB}$ range between $28.5-29.5^{\circ} \mathrm{C}$. The CBS SMP value produced in this study that closest to the SMP of $\mathrm{CB}$ resulted from the blending of PKOs/tengkawang fat $70 / 30$ ratio (w/w), at $31.90{ }^{\circ} \mathrm{C}$. It is estimated that at this temperature, CBS has a solid fat content of only $4-5 \%$. It means that when the CBS is in the mouth (when consumed), it is already very liquid and almost perfect melting. The relationship between the PKOs/tengkawang fat ratio and the SMP of CBS is illustrated in Figure 2. 


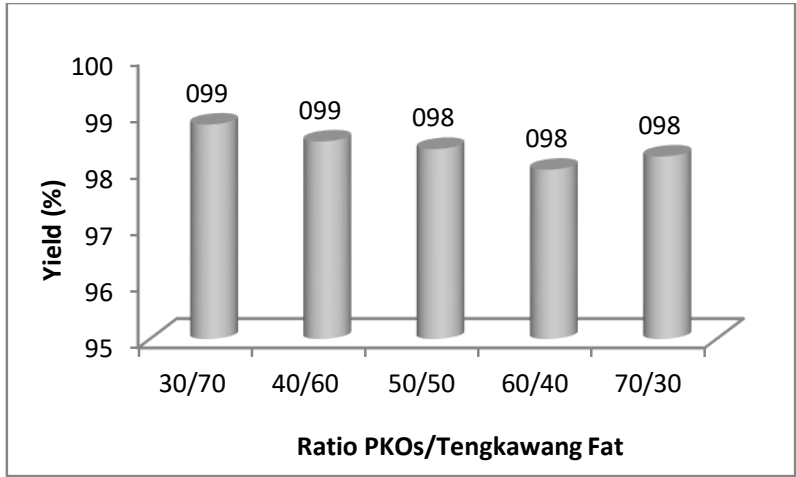

Figure 1 The relationship between PKOs/fat tengkawang ratio and CBS yield.

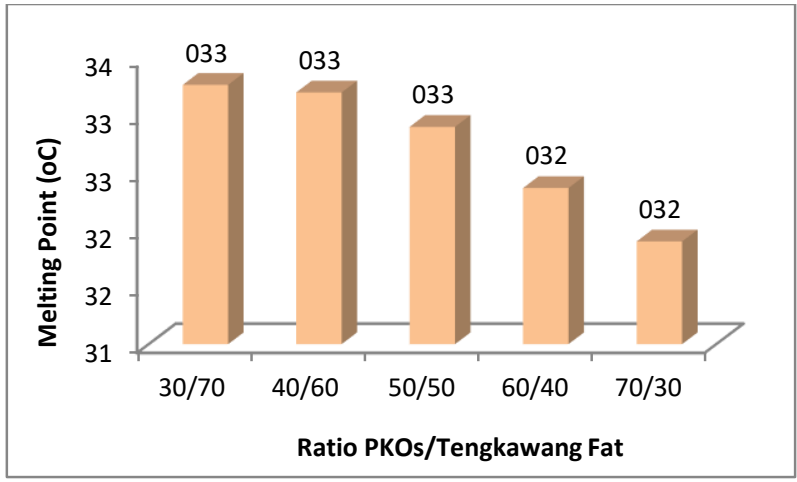

Figure 2 The relationship between PKOs/fat tengkawang ratio and CBS melting point.

\section{CONCLUSION}

The PKOs/tengkawang fat ratio strongly affects the characteristics of the CBS produced. In compositions with the amount of PKOs equal to or slightly more than $\mathrm{LT}$, the resulting CBS melting point and SFC profile were closer to the melting point and SFC profile of CB. It is suggested to produce CBS with a profile that has the closest physical properties to $\mathrm{CB}$ obtaining from blending PKOs with tengkawang fat in the ratio of (30:70).

\section{AUTHORS' CONTRIBUTIONS}

The authors confirm contribution to the paper as follows: study conception and design: first and second. Author; data collection: first and second author; analysis and interpretation of data: first author; draft manuscript preparation: first and second author.

\section{ACKNOWLEDGMENTS}

The gratitude conveyed to the LP2M UNJA for the 2020 program funding and Agricultural Fakulty that have provided research facilities.

\section{REFERENCES}

[1] A. Bahari, C. C. Akoh. 2018. Texture, rheology and fat bloom study of 'chocolates' made from cocoa butter equivalent synthesized from illipe butter and palm mid-fraction. LWT-Food Sci. Technol. 97: 349-354. DOI: 10.1016/j.lwt.2018.07.013.

[2] B. Naik, V. Kumar, 2014. Cocoa butter and its alternatives: a reveiw. Journal Of Bioresource Engineering And Technology, 1: 07-17.

[3] I.S.M. Zaidul, N.A.N Norulaini, A.K.M Omar, RL Smith Jr. 2007. Blending of supercritical carbon dioxide (SC-CO2) extracted palm kernel oil fractions and palm oil to obtain cocoa butter replacers. Journal of Food Engineering 78: 13971409.

[4] G. Calliauw, I.Foubert, W. De Grevt, P Dijckmans, M Kellens, K Dewettinck. 2005. Production of cocoa butter substitutes via two-stage fractionation of palm kernel oil. J. Am. Oil Chem. Soc 82: 783789.

[5] S. Hashimoto, T. Nezu, H. Arakawa, T. Ito, S. Maruzeni. 2001. Preparation of sharpmelting hard palm midfraction and its use as hard butter in chocolate. J. Am. Oil Chem. Soc. 78 (5): 455-460.

[6] D. Undurraga, A. Markovits, S. Erazo. 2001. Cocoa butter equivalent through enzymic interesterification of palm oil mid-fraction. Process Biochemistry 36: 933-939.

[7] P. Kaphueakngam, A. Flood, S. Sonwai. 2009. Production of cocoa butter equivalent from mango seed almond fat and palm oil mid-fraction. Asian Journal of Food and Agro-Industry 2 (04): 441-447.

[8] G. Lakshminarayana, T. Chandrasekhara-Rao, P. A. Ramalingaswamy. 1983. Varietal variations in content characteristics and composition of mango seed and fat. J. Am. Oil Chem. Soc. 60 (1): 88-89.

[9] J. A. Solis-Fuentes, (1998). El aprovechamiento de residuos solidos yliquidos de la agroindustria alimentaria, cinco ejemplos. M.S. Thesis. Facultad de Quimica, UNAM. Mexico.

[10] B. Maheshwari, S. Y. Reddy. 2005. Application of kokum (Garcinia indica) fat as cocoa butter improver in chocolate. Journal of the Science of Food and Agriculture 85: 135-140.

[11] S. Y. Reddy, J. V. Prabhakar. 1994. Cocoa butter extenders from Kokum (Garcinia indica) and Phulwara (Madhuca butyracea) butter. J. Am. Oil Chem. Soc. 7: 217-219.

[12] F. D. Gunstone. 2011. Vegetable Oils in Food Technology Composition, Properties and Uses. In Extraction, Refining and Processing Vegetable Oils: Production, Consumption and Trade Some Topical Issues References, 2nd. Willy-Blackwell, CRC Press, Boca Raton, FL, USA. pp 291-343. 
[13] S. Y. Reddy, J. V. Prabhakar. 1994. Cocoa butter extenders from Kokum (Garcinia indica) and Phulwara (Madhuca butyracea) butter. J. Am. Oil Chem. Soc. 7: $217-219$.

[14] S. Y. Reddy, J. V. Prabhakar. 1989. Confectionery fats from sal (Shorea robusta) fat and phulwara (Madhuca butyracea) butter. Food Chemistry 34(2): $131-139$.

[15] J. O. Olajide, BIO Ade-Omowaye, ET Otunola. 2000. Some physical properties of shea kernel.
Journal of Agricultural Engineering Research 76: 419-421.

[16] Lida HMDN, Ali ARM. 1998. Physicochemical characteristics of palm-based oil blends for the production of reduced fat spreads. J Am Oil Chem Soc, 75: 1625-1631.

[17] Yanty NAM, JMN Marikkar, M Shuhaimi. 2013. Effect of fractional crystallization on the composition and thermal properties of engkabang (Shorea macrophylla) seed fat and cocoa butter. Grasas y aceites, 64 (5): 546-553. 